\title{
RELAÇÃO ENTRE FAMÍLIA E ESCOLA NA PEDAGOGIA DA ALTERNÂNCIA: UM ESTUDO NO TERRITÓRIO DA CANTUQUIRIGUAÇU
}

\author{
RELATIONSHIP BETWEEN FAMILY AND SCHOOL IN ALTERNATION \\ PEDAGOGY: A STUDY ON THE TERRITORY OF CANTUQUIRIGUAÇU
}

\author{
SANTOS, Cilmara Cristina \\ cilmara@unilagos.com.br
}

Faculdade Unilagos

TEIXEIRA, Edival Sebastião

edival@utfpr.edu.br

Universidade Tecnológica Federal do Paraná

\begin{abstract}
RESUMO O artigo resulta de pesquisa que teve por objetivo analisar como ocorrem as relações entre família e escola no contexto da Pedagogia da Alternância desenvolvida em duas Casas Familiares Rurais situadas no Território da Cantuquirguaçu, Estado do Paraná. Os dados foram obtidos através de questionários e entrevistas com docentes, discentes e familiares de alunos. A análise procurou comparar o que dizem professores e pais acerca dessas relações com o que preconiza teoricamente a Pedagogia da Alternância sobre a participação da família na educação escolar dos jovens. Os resultados indicam que, se por um lado, todos os atores envolvidos na pesquisa consideram relevante a participação da família na educação dos jovens pelo método da alternância, por outro, há fatores que dificultam bastante essa ação.
\end{abstract}

PALAVRAS-CHAVE: Família. Escola. Pedagogia da Alternância.

ABSTRACT This paper results from research aimed to analyze how occur relationships between families and schools in the context of the Pedagogy of Alternation developed in two Rural Family Houses located in the Territory of Cantuquirguaçu, Paraná State. Data were collected by using questionnaires and interviews with teachers, students and families of students. The analysis searched compare what say teachers and parents about of these relations with what advocates theoretically the Pedagogy of Alternation about family participation in school education of young people. The results indicate that on one hand all the actors involved in research consider relevant family involvement in the education of young people by the alternating method, on the other hand there factors that hinder quite this action. 
KEYWORDS: Family. School. Alternance Pedagogy.

\section{INTRODUÇÃO}

A família, independente de sua estrutura ou do contexto social em que se insere, integra diretamente o processo educativo de seus membros, e na Pedagogia da Alternância praticada nas Casas Familiares Rurais (CFRs) não é diferente. As CFRs são instituições de ensino que surgiram na década de 1930, na França, tendo como objetivo principal "propiciar uma educação escolar mais adaptada à realidade dos filhos de pequenos agricultores" (TEIXEIRA; ANTUNES, 2011, p. 952). São escolas-residência, "na qual [nas quais] os jovens estudam não apenas conteúdos voltados à formação científica, como também recebem formação geral e profissional voltada ao contexto e necessidades do campo" (BORGES et al., 2011, p. 9). No Brasil a introdução da Pedagogia da Alternância se deu em 1969, no Estado do Espírito Santo.

No Estado do Paraná, a Pedagogia da Alternância surge em 1986 com a implantação da Casa Familiar Rural de Barracão - atualmente CFR de Bom Jesus do Sul, município da região sudoeste do Paraná, na fronteira com a Argentina (FANK, 2007). Atualmente, das 42 CFRs paranaenses, sete estão localizadas no Território Cantuquiriguaçu.

Na região Sul do Brasil existem 70 Casas Familiares Rurais e duas Casas Familiares do Mar, cuja abrangência compreende 204 municípios. As CFRs nessa região são 42 no Paraná, 22 em Santa Catarina e oito no Rio Grande do Sul; as duas Casas Familiares do Mar estão localizadas no litoral catarinense. Todas essas instituições de ensino estão filiadas à Associação Regional das Casas Familiares Rurais do Sul do Brasil (ARCAFARSUL), a qual foi fundada em junho de 1991 e caracteriza-se enquanto associação cultural e beneficente que objetiva proporcionar aos jovens agricultores a permanência no campo, valorizando o meio em que vivem, visando uma formação integrada com sua realidade (ARCAFARSUL, 2012).

No método da Pedagogia da Alternância se espera que a participação das famílias assuma características de protagonismo, mesmo diante da educação 
escolar dos filhos (REIS, 1984; CUNHA, 2000; SETTON, 2002), pois, nesse método, espera-se que a família do jovem exerça um papel muito mais efetivo do que o que é exercido na escola urbana.

Considerar o sujeito dentro de sua totalidade social, de acordo com suas especificidades e vivências, vem ao encontro dos objetivos preconizados pela Pedagogia da Alternância. Esta é uma proposta educativa que se espera seja pensada pela comunidade e para a comunidade, numa forma de organização que possibilite aos sujeitos sociais tornarem-se protagonistas de sua própria história.

Na Pedagogia da Alternância, o papel e a contribuição da família são fundamentais para a inter-relação entre o conhecimento prático e o conhecimento escolar. Por isso, Gimonet (2007, p. 82) afirma que "a educação é um todo e só vale pela unidade que sabe estabelecer-se entre os diferentes meios: família, escola, exterior".

As principais características das CFRs são: a responsabilidade das famílias na gestão de uma associação de pais e alunos; a alternância dos períodos entre o meio de vida socioprofissional e a Casa Familiar onde o educando exerce na prática uma concepção dialética de formação; a vida dos educandos em pequenos grupos e em internatos; uma equipe de formadores denominados monitores, e uma pedagogia adaptada que se chama Pedagogia da Alternância (NASCIMENTO, 2009, p. 168).

Dessa forma, pois, família e CFR devem se articular para que se efetive um ensino com bases sólidas, onde "os pais são chamados a participar de toda a vida da escola, desde o acompanhamento integral dos filhos quando estão junto à família até na administração, coordenação e manutenção da escola" (NASCIMENTO, 2009, p. 168).

De acordo com autores tais como Calvó (1999; 2002), Gimonet (2007) e Nascimento (2009), a Pedagogia da Alternância sustenta-se em quatro pilares: o primeiro é a constituição de uma associação responsável pelas Escolas Familiares Rurais, pois para que estas existam e se fortaleçam é necessário que constituam uma organização comunitária de base participativa, em que a associação das famílias, as instituições locais, os profissionais do setor são os responsáveis pela gestão e pelo desenvolvimento local. 
Calvó (1999, p. 5) define os Centros de Formação por Alternância, dentre os quais estão as CFRs, como uma "associação de famílias, pessoas e instituições que buscam solucionar a problemática comum da evolução e do desenvolvimento local através de atividades de formação, principalmente dos jovens, sem, entretanto excluir os adultos".

Esse pilar da Pedagogia da Alternância é, pois, condição necessária à formação e manutenção de uma CFR, "porque sua existência se vincula a uma organização local de base participava, em que a associação das famílias, as comunidades, as instituições locais, os profissionais do setor são os responsáveis pela gestão e pelo desenvolvimento local" (CALVÓ, 1999, p. 15). Essas associações "não devem se confundir com as tradicionais associações de pais e mestres, que, de modo geral, existem para dar apoio externo à escola na qual estudam seus filhos" (CALVÓ, 1999, p. 15).

O segundo pilar refere-se à própria proposta Pedagógica da Alternância. Segundo Gimonet (1999, p. 44), significa "alternância de tempo e de local de formação, ou seja, de períodos em situação socioprofissional e em situação escolar". Dessa forma, os educandos inter-relacionam ambiente escolar e familiar, o que favorece, por sua vez, o fortalecimento dos vínculos familiares com a escola.

Num sentido amplo, alternância significa, conforme contemplado nos estudos de Calvó (1999, p. 17), um "conjunto dos períodos formativos que se repartem entre o meio socioprofissional (seja na própria família ou na empresa) e a escola. Isto sempre dentro de uma interação educativa escola-meio".

O terceiro pilar da Pedagogia da Alternância consiste na "formação integral da pessoa, de modo a lhe permitir o desenvolvimento pleno da personalidade e a capacidade de construir seu projeto de vida" (CALVÓ, 1999, p. 17). Portanto, considera-se parte do processo educativo das Casas Familiares Rurais todo o contexto social em que o indivíduo está inserido, sua origem, condições econômicas da família e da comunidade, cultura e seus valores.

A chamada formação integral abrange tudo que possa contribuir ou enriquecer a constituição do indivíduo, considerando todos os elementos que se referem ou interferem na aprendizagem, como a organização escolar, a formação dos profissionais, a configuração social, as representações vigentes no meio, o 
projeto de vida de cada um, as condições socioeconômicas da família e da comunidade, dentre outros fatores.

A formação do jovem pela alternância implica, então, o seu envolvimento em atividades produtivas, "de maneira a relacionar suas ações com a reflexão sobre o porquê e o como das atividades desenvolvidas" (SILVA, 2003, p. 24). Ou seja, essa formação busca a interação entre as atividades práticas e a reflexão teórica. Nessa perspectiva educativa "o jovem deve ser o protagonista de sua própria formação" (GIMONET, 2007). Ele deve identificar e sugerir quais conteúdos são relevantes para seu desenvolvimento pessoal e social. Assim, a atenção personalizada é importante nesse processo de formação, "pois a tutoria, o diálogo para revisão do caderno da realidade, as visitas às famílias e às comunidades são alguns dos procedimentos didáticos utilizados para atingir o objetivo da formação integral do aluno" (CALVÓ, 1999, p. 17).

O quarto pilar que sustenta a Pedagogia da Alternância preocupa-se com o desenvolvimento local sustentável. Este prioriza todos os debates e ações que desenvolvam o meio e o mantenham para as futuras gerações. A busca constante das CFRs em promover o desenvolvimento nas comunidades locais é "uma das suas principais características, pois foi este desejo de desenvolvimento local que fez as experiências educativas pautadas na Pedagogia da Alternância surgirem na França e expandirem-se para outros países" (SOUZA, 2011, p. 7).

O desenvolvimento do meio no qual está inserida uma CFR resulta da interação de diferentes atores (FORGEARD, 1999, p. 64), a qual é concretizada dentro de dimensões humanas, econômicas, sociais, culturais, ambientais, numa perspectiva ampla, ou seja, totalizadora ou global. A partir da interação dos sujeitos, quando há interesses em comum, são conduzidas ações de desenvolvimento de competências, de atitudes, de comportamentos visando o bem estar econômico e social das pessoas que vivem nesse meio (FORGEARD, 1999). Portanto, quando os atores de um determinado contexto compartilham interesses de desenvolvimento em comum, eles podem utilizar as CFRs como "espaço de socialização de suas ideias e como lugar de partida para as ações e concretização dessas ideias" (SOUZA, 2011, p. 7). 
Assim, ainda que tenha sido feita apenas uma breve apresentação dos pilares da Pedagogia da Alternância, pode-se perceber a importância dada à participação das famílias nesse método pedagógico. Com efeito, os pais, além de constituírem uma associação para a manutenção das escolas, a qual abrange aspectos jurídicos, econômicos e de gestão, são considerados principalmente como coeducadores no processo de ensino e aprendizagem de seus filhos (CALVÓ, 1999). Ou seja, nessa pedagogia o jovem não é apenas mais um aluno na escola, "mas já um ator num determinado contexto de vida e num território. Sua família é convidada a participar ativamente de sua educação, de sua formação, acima de tudo porque é jovem" (GIMONET, 2007, p. 19).

Tanton (1999, p. 100) entende que as instituições que praticam a Pedagogia da Alternância atualmente surgem "porque os pais querem, por um lado, permanecer implicados na educação de seus filhos" e, "por outro lado, agir coletivamente para um desenvolvimento rural planejado e a serviço da comunidade".

Enfim, esses pilares são concretizados porque há envolvimento entre os diferentes atores sociais durante todo o processo educativo e a relação família e escola é fundamental para o desenvolvimento da educação na perspectiva da Pedagogia da Alternância. Fank (2007, p. 125) apresenta em seus estudos que "todas as ações realizadas pelas famílias no dia-a-dia, no trabalho, no lazer, na organização da propriedade, enfim, nos diversos momentos de interação entre pais e filhos, têm presente uma dimensão educativa". Continua a autora, afirmando que a relação entre pais e filhos torna-se educativa de maneira consistente e total, não só no aprendizado de técnicas de trabalho ou da organização da propriedade, pois "em muitas dessas ações, incorporam-se aprendizagens e saberes humanos, religiosos e culturais, profissionais e costumes que, muitas vezes, são passados de pais para filhos por várias gerações".

É por essa razão que Oliveira (2008, p. 391) defende em seu trabalho que não se pode desprezar o conhecimento que os pais têm no contexto da agricultura, pois dessa forma é possível ligar "o conhecimento da escola com o saber da propriedade" em benefício de todos os envolvidos no processo, sobretudo, da comunidade. 
Então, tomando-se como pressuposto que a família exerce um papel fundamental na educação escolar dos filhos que se processa pelo método da alternância, desenvolveu-se a pesquisa ora relatada a qual teve por objetivo analisar como se processam as relações entre família e escola no contexto da Pedagogia da Alternância desenvolvida nas casas familiares rurais de Candói e de Rio Bonito do Iguaçu, municípios situados no Território da Cantuquirguaçu, Estado do Paraná.

\section{A BASE TERRITORIAL DA PESQUISA}

O Território da Cantuquiriguaçu abrange 21 municípios, sendo eles: Campo Bonito, Candói, Cantagalo, Catanduvas, Diamante do Sul, Espigão Alto do Iguaçu, Foz do Jordão, Goioxim, Guaraniaçu, Ibema, Laranjeiras do Sul, Marquinho, Nova Laranjeiras, Pinhão, Porto Barreiro, Quedas do Iguaçu, Reserva do Iguaçu, Rio Bonito do Iguaçu, Três Barras do Paraná, Virmond e Palmital, constituintes do Médio Centro Oeste do Paraná. Esse território é mantido pela Associação dos Municípios da Catuquiriguaçu, conhecida como Cantu, fundada em 7 de agosto de 1984.

O território é delimitado ao norte pelos rios Piquiri e Cantu e ao sul pelo rio Iguaçu, derivando daí seu nome - Cantuquiriguaçu. Sua extensão é de 13.959,744 quilômetros quadrados e população de 232.551 habitantes, o que representa 2, 2\% da população do Estado do Paraná, dos quais 106.973 (46\%) vivem em áreas rurais e 125.578 em áreas urbanas de acordo com dados do censo demográfico do IBGE 2010.

Nesse espaço territorial vivem 20.528 agricultores familiares, existem 4.216 famílias assentadas, há três comunidades quilombolas e duas terras indígenas demarcadas. De acordo com o diagnóstico socioeconômico realizado pelo Conselho de Desenvolvimento do Território Cantuquiriguaçu - CONDETEC, o Cantuquiriguaçu apresenta 26.159 famílias situadas abaixo da linha da pobreza, sendo 10.252 delas residentes na zona urbana e 15.908 na zona rural. A esse quadro soma-se um déficit habitacional no meio urbano, pois muitas famílias têm buscado melhores condições de vida nas zonas urbanas de seus próprios municípios (CONDETEC, 2004; 2011). 
O território é profundamente marcado pelas suas características rurais e estrutura fundiária, com predominância de agricultura familiar principalmente de subsistência, contrastando com a existência de grandes propriedades onde predomina o plantio de soja e trigo, produtos de utilização intensiva de tecnologia e voltados ao agronegócio de grande escala. Considerando o território em toda sua extensão, os estabelecimentos de agricultura familiar são em maior número, embora ocupem menor área do que os estabelecimentos voltados ao agronegócio, exceto nos municípios de Rio Bonito do Iguaçu, Três Barras do Paraná e Virmond, onde os estabelecimentos de agricultura familiar são em maior número e ocupam maior área (CONDETEC, 2011).

Ante o quadro socioeconômico, o CONDETEC organizou metas e estratégias para o desenvolvimento do Território Cantuquiriguaçu. Dentre os eixos prioritários estão: a formação e educação do campo, a formação profissionalizante, o esporte, a cultura e o lazer. No que diz respeito à educação do campo, o documento elaborado pelo Conselho explicita o reconhecimento da Pedagogia da Alternância como parte importante da sua estratégia de desenvolvimento.

É nesse contexto social e territorial que se situam as duas casas familiares rurais de Candói e de Rio Bonito do Iguaçu.

O município de Candói foi instalado em 1993, possui 1.509,059 km² de área e uma população de 14. 983 habitantes, sendo 7.026 residentes na área urbana e 7.957 na área rural (IPARDES, 2012). Esse município faz parte do Território e está dentre os de maior extensão juntamente com Pinhão, Guaraniaçu e Nova Laranjeiras. No entanto, também se caracteriza como estando dentre os de maior concentração de terras, isto é, com grandes propriedades rurais nas mãos de poucos proprietários, tal como em Foz do Jordão e Reserva do Iguaçu (CONDETEC, 2011).

O município de Rio Bonito do Iguaçu também foi instalado em 1993, conta com uma área territorial de $685,189 \mathrm{~km}^{2}$ e 13. 661 habitantes, sendo 3.322 na área urbana e 10.339 na área rural (IPARDES, 2012). Neste estão localizados os dois maiores assentamentos rurais da América Latina: Ireno Alves dos Santos e Marcos Freire, o que explica o predomínio da pequena propriedade rural e o fato de esses 
estabelecimentos ocuparem maior área do que os de agricultura intensiva (CONDETEC, 2011).

A Casa Familiar Rural de Candói foi fundada em 15 de abril de 1994, iniciando suas atividades no ano seguinte e atualmente oferece o Curso Técnico em Agroindústria. No ano de 2012 contava com duas turmas de alunos, sendo 13 alunos no $1^{\circ}$ ano e 16 alunos no $2^{\circ}$ ano do Ensino Médio.

Já a Casa Familiar Rural de Rio Bonito do Iguaçu foi criada no ano de 1997, iniciando suas atividades em 1998. Em novembro de 2012 essa instituição contava com 77 alunos frequentando regularmente as aulas nas modalidades de Ensino Fundamental e Médio, assim distribuídos: 13 alunos no $7^{\circ}$ ano, 14 no $8^{\circ}$ ano, 15 no $9^{\circ}$ ano do Fundamental e 15 no $1^{\circ}$ ano, 15 no $2^{\circ}$ ano e 5 no $3^{\circ}$ ano do Ensino Médio.

\section{A METODOLOGIA}

Para coleta de dados foram utilizados procedimentos usuais na pesquisa qualitativa, em especial observação e entrevista com docentes (professores, monitores e coordenadores), estudantes e pais ou familiares e grupos focais, sendo um grupo com alunos e outro grupo com professores.

Os pais ou familiares dos alunos foram entrevistados na ocasião de visitas realizadas às suas propriedades rurais. As entrevistas foram semiestruturadas e exploravam, sobretudo, como se processam as relações entre família e escola. Foram entrevistas cinco famílias em Candói e 12 famílias em Rio Bonito do Iguaçu. O roteiro de entrevista elaborado e as visitas a campo buscaram identificar os fatores que motivaram as escolhas dos pais e familiares dos alunos a optarem pela matrícula de seus filhos na CFR ao invés da escola pública mais próxima de sua residência, o significado da Pedagogia da Alternância para cada sujeito entrevistado e como se processa a participação dos pais no cotidiano das CFRs e da formação escolar dos filhos.

Quanto aos monitores, professores e coordenadores das CFRs o foco manteve-se em identificar como estes percebem a diferença entre outras metodologias e a Pedagogia da Alternância, bem como analisar como são 
organizadas ações que favoreçam a participação da família na escola, pois eles são interlocutores que contribuem e influenciam diretamente nesse processo.

No que se refere aos alunos, buscou-se compreender como estes percebem a Pedagogia da Alternância, sua aplicação prática no cotidiano na propriedade da família e de que maneira seus pais e familiares participam da sua formação escolar.

$\mathrm{Na}$ CFR de Candói o grupo focal formado por monitores, professores e coordenadora totalizou cinco participantes. Quanto aos alunos, participaram do grupo todos que estavam presentes no dia da coleta de dados do primeiro e segundo anos, totalizando 15 jovens.

$\mathrm{Na}$ CFR de Rio Bonito do Iguaçu, foram organizados três grupos focais, sendo o primeiro formado por monitores, professores e coordenador totalizando sete participantes. O segundo grupo foi composto por 20 alunos do Ensino Médio e o terceiro por 12 alunos do Ensino Fundamental.

A seleção dos sujeitos entrevistados e que participaram dos grupos focais foi realizada aleatoriamente, a partir de visitas agendadas às unidades de ensino antecipadamente, utilizando enquanto estratégia os dias destinados ao cumprimento de hora atividade dos professores e monitores para abordar um público maior a ser pesquisado nestas funções.

Elegeu-se a abordagem qualitativa de análise dos dados, pois propicia uma análise profunda e "em constante interação com o ecológico, o nível dos significados, motivos, aspirações, atitudes, crenças e valores, que se expressa pela linguagem comum e na vida cotidiana" (MINAYO; SANCHES, 1993, p. 245).

Como não há diferenças significativas entre as Casas Familiares Rurais no que refere aos resultados da pesquisa, as discussões a seguir consideram ambas as instituições.

\section{4 a RELAÇÃO ENTRE FAMílIA E ESCOLA NAS CFRS DE CANDÓI E RIO BONITO DO IGUAÇU}

Para conhecer os motivos e razões que levaram os familiares a matricular seus filhos nas CFRs, questionamos os sujeitos nesse sentido. Dentre as diversas justificativas pela escolha, destacou-se nas respostas a relação entre formação 
escolar e trabalho mais facilmente percebida pelos pais na Pedagogia da Alternância do que na escola de tipo urbano.

Assim, os resultados obtidos na pesquisa apontam para a preocupação dos pais quanto à formação específica voltada à agricultura, pois estes entendem que os conhecimentos adquiridos pelos filhos na CFR podem contribuir com as atividades realizadas no cotidiano para manutenção e subsistência familiar, conforme podemos observar nos exemplos de fragmentos de entrevista a seguir:

\begin{abstract}
Ele na verdade achou que tinha mais fundamento lá, que lá tinha mais prioridade de aprender alguma coisa. A gente que mora na lavoura, daí ele achou melhor lá e tá se adaptando bem lá. (Familiar CFR Rio Bonito do Iguaçu)

O motivo é que a gente trabalha na roça, então na Casa Familiar adquire conhecimento pra depois ajudá na lavora. (Familiar CFR Rio Bonito do Iguaçu)

O incentivo na verdade foi do meu tio que teve a filha deles que estudava ali, daí pra gente que tá na agricultura [...] eles vão aprender uma coisa que incentive mais tarde pra ajudá a gente. (Familiar CFR Candói)

O padrasto dele mais que incentivou mais ele, porque ele não gostava de estudar no colégio aqui, queria ir pra um colégio agrícola, [...] daí foi pra lá, e eu não me arrependo de ter posto ele lá. Ele tá gostando, ele tá levando mais a sério os estudos, é o que ele gosta de fazer, porque a gente já é da agricultura né. É um meio de manter ele nesse ramo da agricultura, então pra mim tá sendo excelente ele lá. (Familiar CFR Candói)
\end{abstract}

A partir desses dados podemos inferir que a opinião dos sujeitos está coerente com os pressupostos da Pedagogia da Alternância, a qual surgiu para atender as demandas e necessidades da população do campo visando uma formação que relacionasse teoria e prática, formando os indivíduos para permanecer no campo.

Outra situação também contemplada durante as entrevistas foi a questão da dificuldade de acesso à escola. Por residirem em propriedades rurais cujo acesso por terra é precário, quando chove o ônibus não consegue fazer o traslado dos alunos entre a residência e CFR. Contudo, essa situação é amenizada por conta da alternância de tempos e espaços de formação, pois a permanência de uma semana na escola em regime de internato obviamente prescinde de transporte diário. Então essa também é uma razão que leva os pais a matricularem seus filhos nas CFRs.

Considerando que a relação entre teoria e prática integra o que preconiza a Pedagogia da Alternância, questionamos os familiares se os mesmos acompanham e colaboram com as atividades que os filhos levam para desenvolver na 
propriedade, tendo em vista que o segundo pilar desta metodologia pauta-se na alternância entre ambiente escolar e familiar visando à formação socioprofissional dos jovens (GIMONET, 1999; CALVÓ, 1999; SILVA, 2003).

Tendo-se que a escolaridade das famílias entrevistadas está em média nas séries iniciais do Ensino Fundamental. Quase todos os entrevistados manifestaram possuir pouco conhecimento sobre os conteúdos escolares, afirmando que colaboram pouco nas atividades dos filhos nesse sentido. No entanto, quando a entrevistadora intervinha e questionava sobre aquelas orientações que transmitem para seus filhos que relacionam teoria e prática, os mesmos afirmavam com entusiasmo que conseguiam colaborar no processo educativo dos filhos.

Então, no que se refere à participação da família para a aprendizagem dos filhos no método da Pedagogia da Alternância, os familiares fizeram manifestações como as que seguem:

Toda vida, ele traz bastante coisa pra ver em casa, ele me ajuda, às vezes eu peço pra ele me ajudar, às vezes que eu também não sei e ele me ajuda né. O que ele aprende lá e ajuda a gente, e a gente também ajuda ele, ainda mais agora que a gente vai fazer plantio do negócio de horta né. Mas muita coisa ele não sabe, daí ele ajuda a gente e a gente ajuda ele, a gente vai trabalhando junto daí né. (Familiar CFR Candói)

Com certeza né, com certeza é muito importante. Tem alguma coisa na lavora que a gente pode explicar, dizer olha é assim ou não é assim né, porque ele começou tá fazendo dois anos que ele tá lá na casa familiar rural, então ainda é pouco tempo dele lá né então muitas coisas ele aprende, ele trás coisas novas de lá pra casa também né, explica pra gente como se planta, como não se planta, como que é, como que não né. (Familiar CFR Candói)

Ah! sim, é muito importante né porque o que elas aprendem lá elas trazem pra nós e o que nós sabemos aqui eles levam pra lá né. Eles repassam um pro outro e depois um sabe uma coisa, outro sabe outra e depois eles repassam um pro outro lá né. (Familiar CFR Rio Bonito do Iguaçu)

Eu acho que é. Por causo que, ele fica assim mais... quando a gente vai lidá com qualquer coisa tipo da agricultura, ele fala: não vó, não é assim, tem que fazer por ali né, que a gente tá aprendendo lá, tem que fazer assim, daí vai na horta né, ele fala assim: não é pra queimar [...] tem que ponhá nos pé das árvore, e faz tempo que a gente pegô esse costume de ponhá nos pé dos arvoredo, pode ver as laranjeira lá, tá pela metade. (Familiar CFR Rio Bonito do Iguaçu)

Assim, o que os dados revelam é que a relevância atribuída pelos entrevistados à participação da família no processo de ensino aprendizagem dos 
filhos é notória, principalmente no que se refere à troca de experiência entre pais e filhos. Nota-se também que o trabalho desenvolvido pelos filhos na propriedade é bastante destacado. Na troca de experiências os pais são considerados, conforme consta nos estudos de Calvó (1999), como coeducadores. Assim, a família participa ativamente da formação dos filhos, o que está de acordo com ideias contidas nos estudos de Gimonet (2007).

Então, no fundo, os dados que obtivemos sugerem fortemente que os pais estão se dando conta de que os conhecimentos que possuem sobre a prática do trabalho na agricultura favorecem bastante o aprendizado escolar dos filhos e se relacionam diretamente com os conteúdos desenvolvidos nas CFRs pesquisadas.

Neste mesmo questionamento realizado com os alunos das CFRs, também foi apontada relevância para a contribuição dos pais e familiares. No entanto, as técnicas desconhecidas pelos pais que podem ser aplicadas na propriedade nem sempre são aceitas pelos mesmos. Os alunos apontaram, em alguns momentos, dificuldades na aceitação dos pais destes novos conhecimentos:

Lá nós conversamos né, eu colocando o que dá pra gente fazê, [...] tentando fazê de uma forma que fique mais fácil de fazê né, e que eles entendam também, por exemplo, eles num tinham muito conhecimento do que é lixo orgânico e reciclável é uma coisa que eles num tinham muito conhecimento que tinha que colocar separado. (Estudante CFR Candói)

Que nem tipo o pai lá na casa sabe mais, que nem remédio prá aplicá, que nem aqui né é mais remédio pra vaquinha e coisarada lá ele já sabe né. (Estudante CFR Candói)

Na verdade aqui a gente aprende né e o que eles já sabem tem que tentá melhorá né, quanto mais a gente aprende melhor continua lá na propriedade. (Estudante CFR Candói)

Quem manda na família é o pai, se o pai não deixa fazê aquela prática, não tem, se família deixar fazer aquela prática [...] se o pai deixá eu faço se o pai não deixa não faz. A melhor coisa é quando o pai concorda sabe pra podê ajudá e incentivá se o pai não concorda ai não tem como fazê, se o pai concorda ai tudo funciona melhor. (Monitor CFR Rio Bonito do Iguaçu)

Assim, para os jovens, os conhecimentos que os pais possuem são de fundamental importância para o processo de aprendizagem. Os fragmentos apresentados a seguir vêm ao encontro do que preconiza a Pedagogia da Alternância, ressaltando a importância do diálogo e troca de experiência entre pais e filhos: 
É muito importante, o que a gente aprende aqui a gente passa pra eles e eles também passam o que sabem pra nós. (Estudante CFR Rio Bonito do Iguaçu)

Sim, quando eles ajudam a gente, eles sempre sabem alguma coisa a mais que a gente não sabia antes, daí eles vão ensinando e nóis vamo aprendendo. (Estudante CFR Rio Bonito do Iguaçu)

É importante eles ajudam a gente e eles também aprendem mais. (Estudante CFR Rio Bonito do Iguaçu)

A convivência com a família se torna melhor né porque você vai dialogar né, você vai conversar, você num vai chegar e impor, primeiro você tem um diálogo e depois você coloca em prática, e também a convivência com a família se torna melhor e a também a troca de experiências, o que você sabe de coisa novo, o pai também ele tem o conhecimento dele e também tem coisas que ele já sabia e que você num sabe, tipo receitas de caldos pra passar nas plantas, já vem de família essa troca de informações, isso é bom. (Monitor CFR Rio Bonito do Iguaçu)

Face ao exposto, podemos inferir que tanto os jovens quanto seus pais percebem que há contribuição mútua para o crescimento de ambos, propiciado pelos seus respectivos conhecimentos. E aqui há que se ressaltar que a Pedagogia da Alternância, diferentemente do que se observa em geral nas escolas urbanas, incentiva essa relação, o que é bem compatível, diga-se, com o método que preconiza que os pais têm o papel de acompanhar e contribuir com o aprendizado dos educandos (GIMONET, 1999; CALVÓ, 1999; SILVA, 2003; SETTON, 2002).

$\mathrm{Na}$ perspectiva dos docentes essa relação também é importante e se diferencia do ensino em geral, pois exige um acompanhamento dos familiares nas atividades que são levadas para fazer em casa.

Quando questionados quanto à importância da participação da família no método da Pedagogia da Alternância, diversos foram os apontamentos por parte dos professores, monitores ou coordenadores, como nos exemplos a seguir:

É importante, desde a educação que eles recebem na casa né. A gente busca mostrar pra essa família estar discutindo, e toda semana comparecer com as obrigações na escola. Já cobrando a lição regular, já pra família tá conhecendo. Eles têm tarefa né, que toda semana tá mostrando o caderno pra família, discutindo as questões com a família, então a família está a par né, [...] mas é uma chance a mais pra estar acompanhando. (Monitor na CFR de Candói).

É eu acho que os pais são mais participativos porque têm que aplicar na propriedade. É uma nova experiência. (Professor na CFR de Candói). 
$\mathrm{Na}$ realidade a escola leva os pais a participar, diferente da escola regular, os alunos às vezes, saem brincar, saem se divertir, ou fazer qualquer outra coisa, aqui os alunos têm que participar na família, todo mundo trabalha, todo mundo ajuda também. (Professor na CFR de Candói).

Percebe-se que a participação familiar nesses relatos está relacionada ao acompanhamento das atividades escolares. No entanto, houve outras manifestações que se referem à aplicação de práticas ou novas técnicas na propriedade, bem como às atividades que devem ser acompanhadas pelos pais e depois partilhadas pelos jovens quando estão internados nas CFRs:

A gente vê também que essa participação da família, vou dizer os pais mais velhos, então eles tentam mudar a cabeça desses pais mais velhos, então eles vêm, às vezes, falar pra mim, eu vou ter que chegar em casa e... eles levam muitas aulas práticas, pra eles aplicarem na prática o que eles discutiram na teoria aqui na sala, e às vezes, a gente quer saber como eles viram, como eles aprenderam, e às vezes eles sentem muita dificuldade dos pais aceitarem fazer o que eles estão querendo, também tem isso da família participar e às vezes não aceitar porque são mais velhos, né tem que respeitar também né. [...]. Mas é bem complicado. E na questão do Plano de Estudo que eles têm que levar, tem que fazer com a família e tem que trazer assinado pela família, óbvio, que a gente também tem problema também, já aconteceu deles não fazerem os planos em casa e chegarem aqui na escola pra fazer, aí na hora da leitura, da exposição, não vai ficar natural, aí a gente já nota logo que fez em cima da hora, fez correndo, não fez com a família, faltou o ponto de vista do pai, da mãe, então é importante eles levar e fazer a família entende. (Professor na CFR de Candói).

Eu também no meu ponto de vista a participação da família é muito importante, tanto no acompanhamento das atividades desenvolvidas lá na casa né quanto na liberdade de confiar no aluno e quem sabe deixar ele pôr em prática o conteúdo que ele aprende aqui né, porque a maioria dos alunos a gente percebe quando faz visita, que eles estudam, aprendem o que aprendem não colocam em prática lá na propriedade deles né, se a família der essa abertura pra eles ter essa autonomia de chegar lá e falar: ó pai aprendi que é assim dessa forma, nós podemos implantar aquela atividade aqui em casa né, então eu acho que a família tem que sempre acompanha e também dá essa liberdade pra ele, pra ele consegui colocar em prática aquilo que ele aprende. (Professor na CFR de Rio Bonito do Iguaçu).

Mas, se por um lado a participação da família no processo educativo do método da alternância é reconhecida por todos os atores como bastante relevante, por outro, há problemas importantes para o incremento dessa participação para além dos aspectos mais propriamente relativos aos conteúdos escolares.

De fato, quanto à participação da família nas instituições pesquisadas, os dados que obtivemos demonstram que não há vínculos mais efetivos entre os 
familiares e as CFRs excetuando-se o fato de seus filhos lá estarem matriculados. Com efeito, nenhum dos entrevistados relatou uma forma diferenciada de participar da instituição além de uma ou duas reuniões durante o ano. Também não identificamos famílias que integram alguma associação para gestão escolar conforme preconiza um dos pilares da Pedagogia da Alternância.

Por outro lado, é importante destacar que um dos fatores que pôde ser observado in loco pela pesquisadora durante as visitas às propriedades rurais é que a distância das residências dos familiares é grande em relação à localização da CFR em ambos os municípios. As propriedades se localizam em sua grande maioria em áreas de assentamentos rurais ficando a mais de $50 \mathrm{~km}$ de distância da instituição de ensino. As estradas são de terra ou cascalhadas e quando chove o acesso fica difícil. Conforme relatado por familiares, nem os ônibus que levam crianças para escolas urbanas conseguem chegar até esses locais. E esse foi um dos motivos marcantes pelos quais os pais optaram por matricular seus filhos nas CFRs, como já mencionamos.

Mas, além desse aspecto logístico, o qual é reconhecido como problemático por todos os envolvidos na pesquisa, a metodologia da Pedagogia da Alternância na sua prática cotidiana é algo complexo, pois exige a participação de diferentes atores, como professores, pais e os próprios alunos, todos implicados num mesmo objetivo. Esse processo não é algo que se constrói facilmente. Existem múltiplos fatores que podem interferir, como por exemplo, a condução das CFRs na perspectiva da materialidade de seus quatro pilares fundamentais.

A única coisa assim que dentro da Casa familiar, comparado com o colégio normal é que deveria ter uma associação dos pais como tem no colégio normal. Eu acho é que os pais teriam que participar um pouco mais na parte até da coordenação, da organização, da associação. A gente tem a nossa associação, mas a nossa associação ela não tem esse objetivo, então eu sinto falta de uma associação de pais e mestres como tem na escola normal, pra discutir coisa interna da escola mesmo sabe, e chamar na reunião e os comparecerem, porque a nossa maior dificuldade, como te falei, é de reunir os pais pra poder falar sobre os filhos, nós até tentamos início das aulas, entregar os boletins e chamar um pai de cada vez, e explicar: ó teu filho tá assim, e precisa melhorar assim, e isso eu acho que faz falta, e nós não conseguimos ainda fazer isso, uma porque a distância é muito grande, um mora aqui, outro mora a $40 \mathrm{KM}$ daqui, então teria que ver algum jeito pra tentar conciliar isso. (Professor na CFR de Candói). 
Sobre a participação dos pais na Associação mantenedora de cada CFR pesquisada, os resultados que obtivemos parecem incompatíveis com o que se espera no método da alternância. $O$ relato a seguir bem exemplifica e sustenta essa afirmação:

Os pais são o foco dessa Associação. Só que mesmo assim quando têm as reuniões da Associação, os pais não participam, então eles não têm esse conhecimento do que é uma Associação, pra que que serve essa Associação, e por que eles são importantes pra Associação. Então isso é uma coisa que tem que ser trabalhada. (Professor na CFR de Candói).

Essa fala parece demonstrar que os pais de fato sequer sabem que são associados de alguma instituição. $E$ isso nos parece bem mais problemático para a Pedagogia da Alternância do que as distâncias e as chuvas, porque atinge o âmago do método em um de seus pilares. E um pilar sustenta um edifício e se sustenta, não pode ser considerado apenas no seu aspecto retórico.

Então, o que os nossos resultados apontam é, por um lado, a necessidade de se rever o processo de participação dos pais nas CFRs pesquisadas, pois não basta a existência legal de uma Associação para que se efetive o método da alternância. Por outro lado, contudo, os resultados indicam também que, apesar das limitações impostas pelas distâncias, pela precariedade das estradas rurais e pelo nível socioeconômico das famílias, os familiares entrevistados participam efetivamente da formação escolar de seus filhos intercambiando seus saberes práticos com os saberes que os jovens adquirem nas CFRs.

\section{CONSIDERAÇÕES FINAIS}

O método da Pedagogia da Alternância proporciona aos pais acompanhar e contribuir com o processo de aprendizagem escolar dos filhos. Nesse sentido, os resultados obtidos revelam a notória relevância atribuída pelos entrevistados à participação da família no processo de ensino e aprendizagem dos jovens, principalmente no que se refere à troca de experiência no trabalho da agricultura entre pais e filhos no contexto investigado.

Não obstante, a realização da pesquisa demonstrou também que existem dificuldades para que a relação entre família e escola se efetive como esperado no 
método da Pedagogia da Alternância. Um dos problemas detectados refere-se às distâncias entre as CFRs e as propriedades dos jovens. Outra constatação, e esta mais importante, diz respeito à inexistência de vínculos mais efetivos entre os familiares e as instituições, bem como o conhecimento superficial da função da família nesse método pedagógico. Em outras palavras, um dos pilares fundamentais da Pedagogia da Alternância que preconiza a participação das famílias no processo está sendo desenvolvido de maneira superficial nas CFRs pesquisadas.

Assim, os resultados obtidos demonstram a necessidade de se pensar estratégias que propiciem condições para a efetivação da participação das famílias conforme preconizado pela Pedagogia da Alternância, principalmente porque os familiares entrevistados demonstraram interesse e entusiasmo em participar do processo educativo escolar de seus filhos.

\section{CILMARA CRISTINA SANTOS}

Mestre em Desenvolvimento Regional pela UTFPR. Assistente Social. Docente da Faculdade Unilagos - Mangueirinha/PR.

\section{EDIVAL SEBASTIÃO TEIXEIRA}

Doutor em Educação pela USP. Docente do Programa de Pós-Graduação em Desenvolvimento Regional da UTFPR.

\section{REFERÊNCIAS}

ARCAFARSUL. Site Oficial da Associação Regional das Casas Familiares Rurais do Sul do Brasil. Disponível em: <www.acarfarsul.org.br>. Acesso em maio de 2012.

BORGES, Graziela Scopel; MAYER, Polyane Passos; PALARO, Ricardo; SANTOS, Cilmara Cristina dos; BERNARTT, Maria de Lourdes. Casas Familiares Rurais: histórico de implantação no sudoeste do Paraná. Synergismus scyentifica. UTFPR, Pato Branco, 06 (1). 2011, p. 4-11.

CALVÓ, Pedro Puig. Introdução. In: Pedagogia da Alternância - alternância e desenvolvimento. Primeiro Seminário Internacional. Salvador: Dupligráfica Editora, 1999.

. Formação pessoal e desenvolvimento local. In: Pedagogia da Alternância. Formação em Alternância e Desenvolvimento Sustentável - Anais do I 
Seminário Internacional da Pedagogia da Alternância. Brasília/DF, nov., p. 126-146, 2002.

CONDETEC (Conselho de Desenvolvimento do Território Cantuquiriguaçu). Diagnóstico Socioeconômico, Laranjeiras do Sul, 2004.

. Plano Safra Territorial 2010-2013. Laranjeiras do Sul, 2011.

CUNHA, Marcus Vinícius da. A escola contra a família. In: FARIA FILHO, Luciano Mendes; LOPES, Eliana Marta Teixeira; VEIGA, Cynthia Greive (orgs.). 500 anos de Educação no Brasil. Belo Horizonte: Autêntica, 2000. p. 447- 468.

FANK, Clenir. Entre a enxada e o lápis: a prática educativa da Casa Familiar Rural de Francisco Beltrão/Paraná. Dissertação (Mestrado). Porto Alegre: UFRGS, 2007.

FORGEARD, Gilbert. Alternância e Desenvolvimento do Meio. In: Pedagogia da Alternância - alternância e desenvolvimento. Primeiro Seminário Internacional. Salvador: Dupligráfica Editora, 1999.

GIMONET, Jean Claude. Nascimento e desenvolvimento de um movimento educativo: as Casas familiares Rurais de Educação e Orientação. In: Anais do I Seminário Internacional da Pedagogia da Alternância: Alternância e Desenvolvimento. Salvador: UNEFAB, 1999, p. 39-48.

. Praticar e compreender a pedagogia da alternância dos CEFFAs. Petrópolis: Vozes, Paris, 2007.

IPARDES. Caderno Estatístico do Município de Rio Bonito do Iguaçu. 2012. Disponível em: <http://www.ipardes.gov.br/cadernos/Montapdf.php?Municipio=85340\&btOk=ok>. Acesso em 03 de janeiro de 2013.

MINAYO, Maria Cecilia de S.; SANCHES, Odécio. Quantitativo - Qualitativo: Oposição ou complementaridade? Cadernos de Saúde Pública. Rio de Janeiro, ENSP/FIOCRUZ, 1993, v. 9, n. 3, p. 239-262.

NASCIMENTO, Claudemiro Godoy do. Gestão democrática e participativa na pedagogia da alternância: a experiência da Escola Família Agrícola (EFA) de Goiás. Revista FACED, Salvador, n. 15, jan./jul, 2009.

OLIVEIRA, Antonio M. de. As Bases Filosóficas e Epistemológicas de Alguns Projetos de Educação do Campo: do Pretendido Marxismo à Aproximação ao Ecletismo Pós-Moderno. Tese (Doutorado em Educação). Universidade Federal do Paraná, Curitiba, 2008.

REIS, José Roberto Tozoni. Família, emoção e ideologia. In: LANE, Silvia; CODO, Wanderley (orgs). Psicologia Social: o homem em movimento. São Paulo, Brasiliense, 1984. 
SETTON, Maria da Graça Jachinto. Família, escola e mídia: um campo com novas configurações. Educação e Pesquisa, v. 28, n. 1, p. 107-116, jan/jun, 2002.

SILVA, Lourdes Helena da. A relação escola-família no universo das experiências brasileiras de formação em alternância. 2003. Disponível em: <www.anped.org.br/reunioes/28/textos/GT03/GT03-475--Int.rtf>. Acesso em $24 \mathrm{de}$ outubro de 2012.

SOUZA, Maria Antônia de. Educação do Campo: Políticas, Práticas Pedagógicas e Produção Científica. Educação \& Sociedade, v. 29, n. 105, p. 1089-1111, set/dez, 2011.

TANTON, Christian. Alternância e Parceria: Família e Meio Sócio-Profissional. In: Anais do I Seminário Internacional da Pedagogia da Alternância: Alternância e Desenvolvimento. Salvador: UNEFAB, 1999, p. 39-48.

TEIXEIRA, Edival Sebastião; ANTUNES, Letícia Cristina. Casas familiares rurais e desempenho escolar: um estudo na região sudoeste do Paraná. Rev. Diálogo Educ., Curitiba, v. 11, n. 34, p. 951-969, set./dez, 2011. 